Case Reports in
Gastroenterology
Case Rep Gastroenterol 2021;15:131-136

DOI: 10.1159/000511864

Published online: February 3, 2021

(C) 2021 The Author(s)

Published by S. Karger AG, Base www.karger.com/crg

This article is licensed under the Creative Commons Attribution-NonCommercial 4.0 International License (CC BY-NC) (http://www.karger.com/Services/OpenAccessLicense). Usage and distribution for commercial purposes requires written permission.

\title{
Pancreatic Metastasis from Malignant Melanoma: Not All That Glitters Is Gold
}

\author{
Jose Vargas-Jiménez ${ }^{a} \quad$ Jorge Vargas-Madrigal ${ }^{b} \quad$ Roberto Arias-Mora $^{b}$ \\ Diana Ulate-Ovares ${ }^{c}$ Bruno Solis-Ugalde ${ }^{d}$ \\ ${ }^{a}$ Department of Gastroenterology and Endoscopy, Hospital La Anexión, Nicoya, \\ Costa Rica; bepartment of Gastroenterology and Endoscopy, Hospital Enrique \\ Baltodano Briceño, Liberia, Costa Rica; 'Department of Pathology, Hospital Enrique \\ Baltodano Briceño, Liberia, Costa Rica; dDepartment of Radiology, Hospital San Juan \\ de Dios, San José, Costa Rica
}

\section{Keywords}

Endoscopic ultrasound - Metastatic melanoma - Pancreatic melanoma - Endoscopic ultrasound-guided fine needle biopsy · Case report

\begin{abstract}
Pancreatic adenocarcinoma is the most common malignancy of the pancreas; on rare occasions, metastatic tumors are present. Differentiating a primary neoplasm from a metastatic one is important for ensuring adequate treatment for the patient. We present a case of metastatic melanoma to the pancreas. A 60-year-old man presented with a history of weight loss, vague abdominal pain, jaundice, and pruritus. Laboratory tests showed increased total bilirubin, with a direct fraction predominance, as well as increased alkaline phosphatase and gamma glutamyl transferase. Imaging studies revealed a mass in the head of the pancreas. Endoscopic ultrasound (EUS)-guided fine needle biopsy was performed, and histologic examination confirmed the diagnosis of metastatic melanoma. This case report illustrates the invaluable use of EUSguided tissue acquisition in the study of pancreatic solid lesions to obtain an accurate diagnosis. Melanomas should always be part of a differential diagnosis when evaluating patients with pancreatic masses.

(C) 2021 The Author(s)

Published by S. Karger AG, Basel
\end{abstract}




\section{Case Reports in Gastroenterology}

Case Rep Gastroenterol 2021;15:131-136 DOI: $10.1159 / 000511864$

(c) 2021 The Author(s). Published by S. Karger AG, Basel www.karger.com/crg

Vargas-Jiménez et al.: Pancreatic Metastasis from Malignant Melanoma

\section{Introduction}

Pancreatic adenocarcinoma is the most common tumor of the pancreas; however, 2-5\% of pancreatic malignancies are metastases [1-3], typically from the kidney, breast, lung, and colon, and rarely sarcomas or melanomas [1,3-5]. Metastatic melanoma has a poor prognosis, as autopsy series have shown that disseminated melanomas frequently affect the gastrointestinal tract in $50 \%$ of cases [6], with roughly $1 \%$ presenting as an isolated pancreatic metastasis [7].

Pancreatic metastases can resemble primary pancreatic tumors on imaging, which is why endoscopic ultrasound (EUS) and fine needle biopsy (FNB) are important tools when examining these lesions. These procedures allow for an optimal characterization of the lesion and, in the majority of cases, a definite diagnosis by taking samples for cytology or histology. Here we present a case of metastatic malignant melanoma of the pancreas diagnosed by EUS-FNB.

\section{Case Report}

A 60-year-old man, with a usual weight of $76 \mathrm{~kg}$, presented to his primary care doctor with a significant weight loss of approximately $15 \mathrm{~kg}$ over a 1-month period, vague abdominal pain, jaundice, and pruritus. No pertinent past medical history was present, and there was no family history of neoplasia. An abdominal ultrasound showed significant dilation of the intraand extrahepatic bile ducts and a mass in the pancreas. The patient was admitted to our hospital for further examination.

On admission, laboratory tests were obtained. The complete blood count was within normal limits. The total bilirubin was $18 \mathrm{mg} / \mathrm{dL}$, with a direct fraction of $10 \mathrm{mg} / \mathrm{dL}$, an alkaline phosphatase of $333 \mathrm{IU} / \mathrm{L}$, and a gamma glutamyl transferase of $145 \mathrm{IU} / \mathrm{L}$. IgG4 levels were within normal limits, and CA19-9 was $51 \mathrm{U} / \mathrm{mL}$.

An enhanced computed tomography (CT) scan revealed a $3.6 \times 4.2 \mathrm{~cm}$ mass located at the posterior aspect of the head of the pancreas. The mass was round, well-defined, with no calcifications or documentation of ganglia or vessel involvement. There was no pancreatic gland atrophy or main pancreatic duct dilation. Magnetic resonance imaging (MRI) showed a $3.4 \times$ $3.5 \times 4.4 \mathrm{~cm}$ mass in the head of the pancreas, with hyperintense enhancement on T1. In addition, there were left para-aortic and peritoneal nodular lesions having the same characteristics on T1 signaling as the pancreatic mass, making them highly suggestive of metastatic infiltration (Fig. 1).

Given these findings, the patient was scheduled for endoscopic retrograde cholangiopancreatography (ERCP) and EUS. The EUS revealed a hypoechoic, heterogeneous mass located at the head of the pancreas. An FNB was performed with an Acquire ${ }^{\mathrm{TM}}$ 19-G needle (Boston Scientific Co., Natick, MA, USA) using the fanning technique. The ERCP showed a long and regular stricture of the mid-distal common bile duct. Therefore, a 10-Fr plastic stent was placed.

Microscopic features of the pancreatic FNB showed normal pancreatic parenchyma with infiltration of a tumor composed of sheets of heavily pigmented and atypical epithelioid cells with a high nuclear-cytoplasmic ratio, eosinophilic cytoplasm, and a hyperchromatic nucleus with marked pleomorphism. Numerous atypical mitoses were observed. Immunohistochemistry stains revealed that the tumor cells had melanocyte differentiation (S100+, HMB-45+, Melan-A/MART-1+), which is consistent with pancreatic infiltration of melanoma (Fig. 2). The FNB specimen also showed heavily pigmented epithelioid cells.

\section{Karger'=}




\section{Case Reports in Gastroenterology}

Vargas-Jiménez et al.: Pancreatic Metastasis from Malignant Melanoma

\section{Discussion}

We report a rare presentation of a metastatic melanoma in the head of the pancreas, with no obvious primary lesion. We assumed that it was metastatic as primary gastrointestinal tract melanoma is quite rare. Disseminated melanoma typically affects the gastrointestinal tract in $50 \%$ of cases [6].

Various diagnostic methods such as CT, MRI, and EUS are sensitive for characterizing pancreatic solid lesions; however, none of these imaging modalities are able to accurately differentiate a primary lesion from a metastatic one. Metastases are usually considered to be small, well-defined masses [8,9], which is why EUS and FNB are the preferred imaging and tissue sampling methods to ensure adequate diagnoses. However, pancreatic metastases of melanomas do show characteristic signal features on MRI. Specifically on T1, the lesion will be hyperintense, indicating changes caused by the paramagnetic properties of melanin $[9,10]$.

When examining a patient with a pancreatic solid lesion, is important to keep in mind all possible causes and to assume that the initial presentation may be deceiving. In our case, the results of our examinations suggested pancreatic adenocarcinoma, but the macroscopic appearance of the FNB sample (Fig. 3) exhibited a markedly dark core, and the signal features of MRI indicated a possible metastatic melanoma. The cytology was suggestive of melanoma, which was later confirmed by immunostaining, which demonstrated reactivity to HMB-45, Melan-A, and S100. Extensive workup was performed when attempting to identify the primary lesion. However, no additional lesions were found, and we were unable to perform a positron emission tomography (PET)-CT to identify additional sites of metastases or primary lesions, as neither our center nor our referral center has a PET-CT machine.

Metastatic melanoma has a poor prognosis, with a median life expectancy of 6-12 months in cases of gastrointestinal metastasis [11]. As our patient also had para-aortic and peritoneal lesions suggestive of metastatic melanoma, surgery was not considered as part of their treatment. Furthermore, evidence regarding the surgical success for metastatic melanomas and other tumors of the pancreas is scarce [12]. Our patient's cholestasis improved with biliary prosthesis and he is being considered for immunotherapy.

Diagnosing a patient with a pancreatic mass can be challenging, and primary tumors and those from other sites should be taken into account. Melanomas should always be part of a differential diagnosis, especially when obtaining a black core upon FNB and hyperintense lesions on MRI. This case illustrates the invaluable use of EUS in the study of pancreatic solid lesions.

\section{Statement of Ethics}

The hospital director and the head of department of Hospital La Anexión approved this case study. Written informed consent of the patient for publication of this case report and any accompanying images was obtained.

\section{Conflict of Interest Statement}

The authors have no conflicts of interest to declare.

\section{Karger'=}




\section{Case Reports in Gastroenterology}

\section{Funding Sources}

There were no funding sources.

\section{Author Contributions}

J. Vargas-Jiménez: data collection, writing of the original draft, review, and editing. J. Vargas-Madrigal: review and editing. R. Arias-Mora: editing. D. Ulate-Ovares: data curation. B. Solis-Ugalde: editing. All authors contributed equally to this article. All authors read and approved the final version of the manuscript.

\section{References}

1 Nakamura Y, Yamada R, Kaneko M, Naota H, Fujimura Y, Tabata M, et al. Isolated pancreatic metastasis from malignant melanoma: a case report and literature review. Clin J Gastroenterol. 2019 Dec;12(6):626-36.

2 Jana T, Caraway NP, Irisawa A, Bhutani MS. Multiple pancreatic metastases from malignant melanoma: conclusive diagnosis with endoscopic ultrasound-guided fine needle aspiration. Endosc Ultrasound. 2015 Apr-Jun;4(2):145-8.

3 Larsen AK, Krag C, Geertsen P, Jakobsen LP. Isolated malignant melanoma metastasis to the pancreas. Plast Reconstr Surg Glob Open. 2013 Dec;1(8):e74.

4 De Moura DT, Chacon DA, Tanigawa R, Coronel M, Cheng S, Artifon ÉL, et al. Pancreatic metastases from ocular malignant melanoma: the use of endoscopic ultrasound-guided fine-needle aspiration to establish a definitive cytologic diagnosis: a case report. J Med Case Reports. 2016 Dec;10(1):332.

5 Portale TR, Di Benedetto V, Mosca F, Trovato MA, Scuderi MG, Puleo S. Isolated pancreatic metastasis from melanoma. Case report. G Chir. 2011 Mar;32(3):135-7.

6 Schuchter LM, Green R, Fraker D. Primary and metastatic diseases in malignant melanoma of the gastrointestinal tract. Curr Opin Oncol. 2000 Mar;12(2):181-5.

7 Pang JC, Roh MH. Metastases to the Pancreas Encountered on Endoscopic Ultrasound-Guided, Fine-Needle Aspiration. Arch Pathol Lab Med. 2015 0ct;139(10):1248-52.

8 Bhosale PR, Menias CO, Balachandran A, Tamm EP, Charnsangavej C, Francis IR, et al. Vascular pancreatic lesions: spectrum of imaging findings of malignant masses and mimics with pathologic correlation. Abdom Imaging. 2013 Aug;38(4):802-17.

9 Franz D, Esposito I, Kapp AC, Gaa J, Rummeny EJ. Magnetic resonance imaging of less common pancreatic malignancies and pancreatic tumors with malignant potential. Eur J Radiol Open. 2014 Sep;1:49-59.

10 Balci NC, Semelka RC. Radiologic features of cystic, endocrine and other pancreatic neoplasms. Eur J Radiol. 2001 May;38(2):113-9.

11 Solmaz A, Yiğitbaş H, Tokoçin M, Gülçiçek OB, Erçetin C, Yavuz E, et al. Isolated pancreatic metastasis from melanoma: a case report. J Carcinog Mutagen. 2014;5(6):202.

12 Sperti C, Moletta L, Patanè G. Metastatic tumors to the pancreas: the role of surgery. World J Gastrointest Oncol. 2014 Oct;6(10):381-92. 


\section{Case Reports in Gastroenterology}
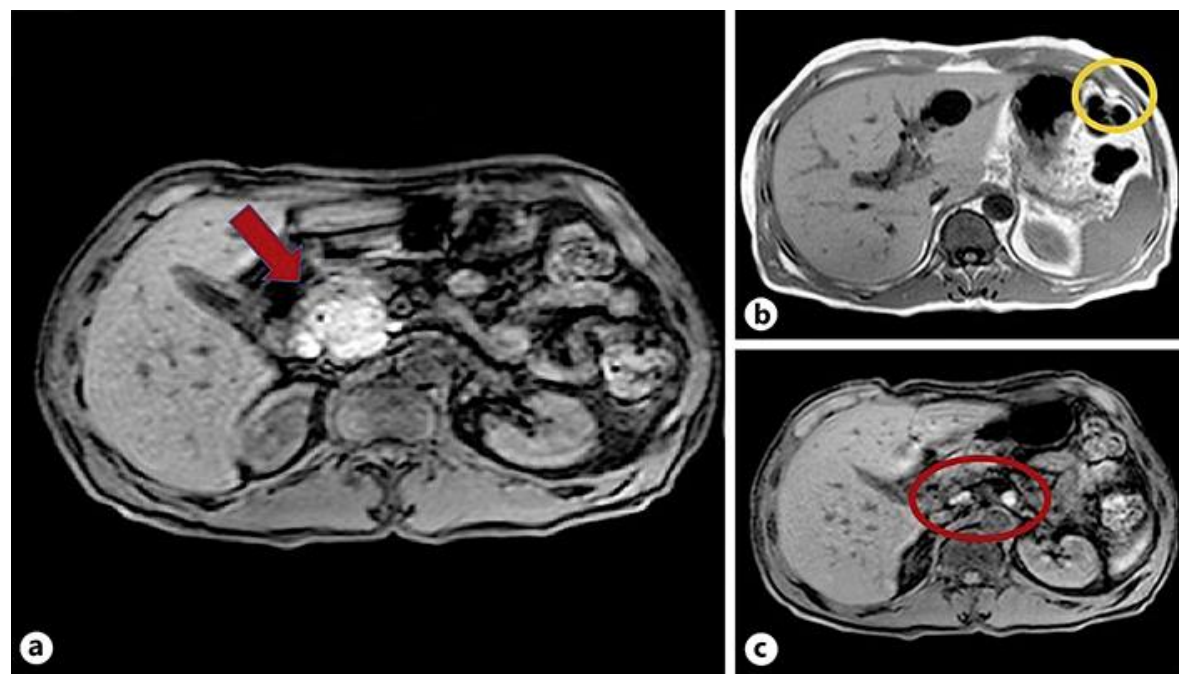

Fig. 1. Magnetic resonance imaging. a Fat suppression on T1 demonstrating a hyperintense pancreatic head mass (red arrow). b, c Peritoneal nodular lesion (b, yellow circle) and para-aortic nodular lesions (c, red circle), with a hyperintense signal on $\mathrm{T} 1$.
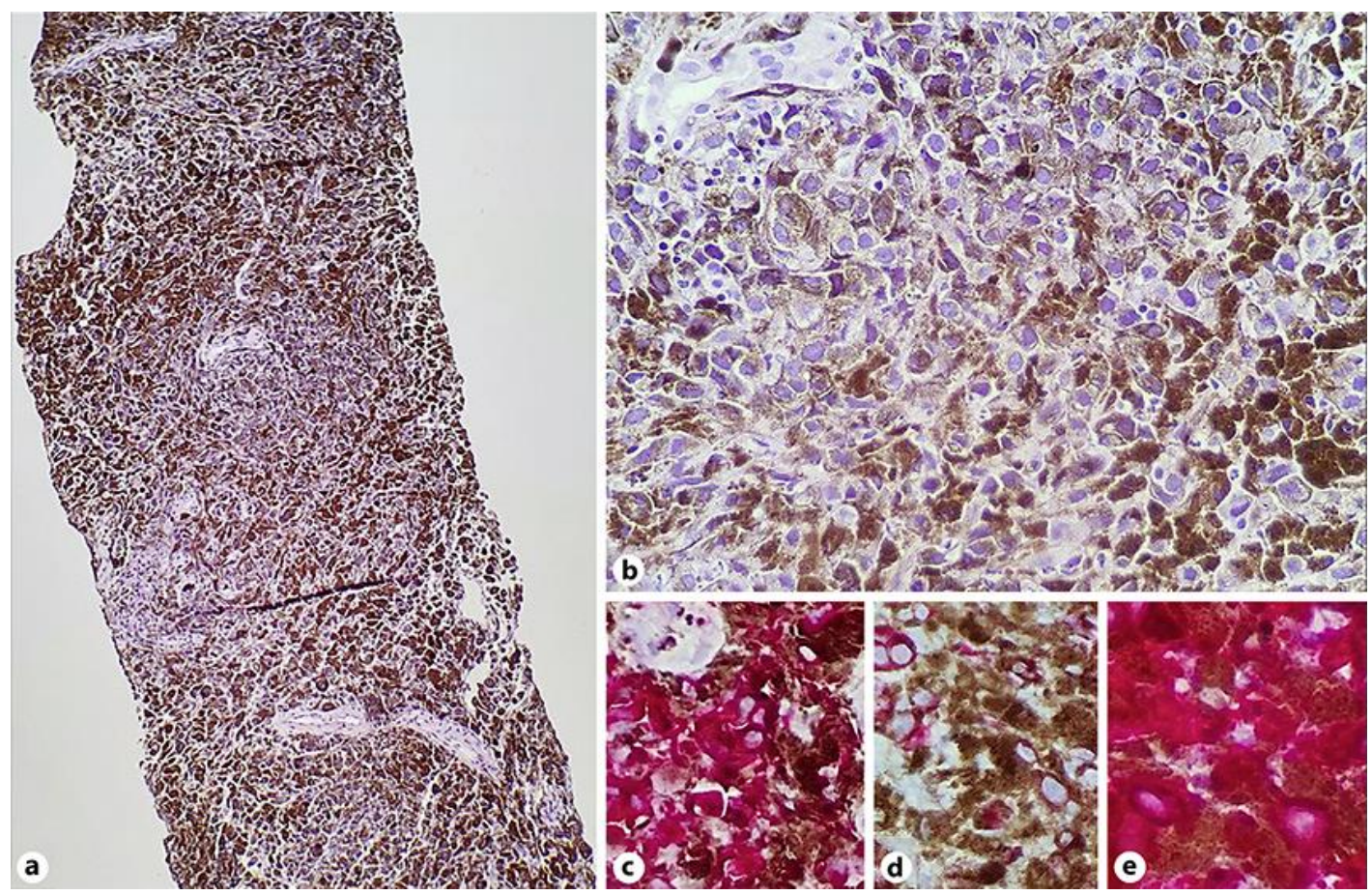

Fig. 2. Microscopic and immunohistochemistry (IHC) findings of the pancreatic fine needle biopsy specimen. a, b Diffuse and intense dark brown pigmented tumor cells, hematoxylin-eosin stain (original magnification: $\mathbf{a} \times 40$ and $\mathbf{b} \times 200$ ). $\mathbf{c}$ Positive HMB-45 IHC stain (original magnification: $\times 200$ ). $\mathbf{d}$ Positive Melan-A IHC stain (original magnification: $\times 200$ ). e Positive S100 IHC stain (original magnification: $\times 200$ ). 

www.karger.com/crg

Vargas-Jiménez et al.: Pancreatic Metastasis from Malignant Melanoma
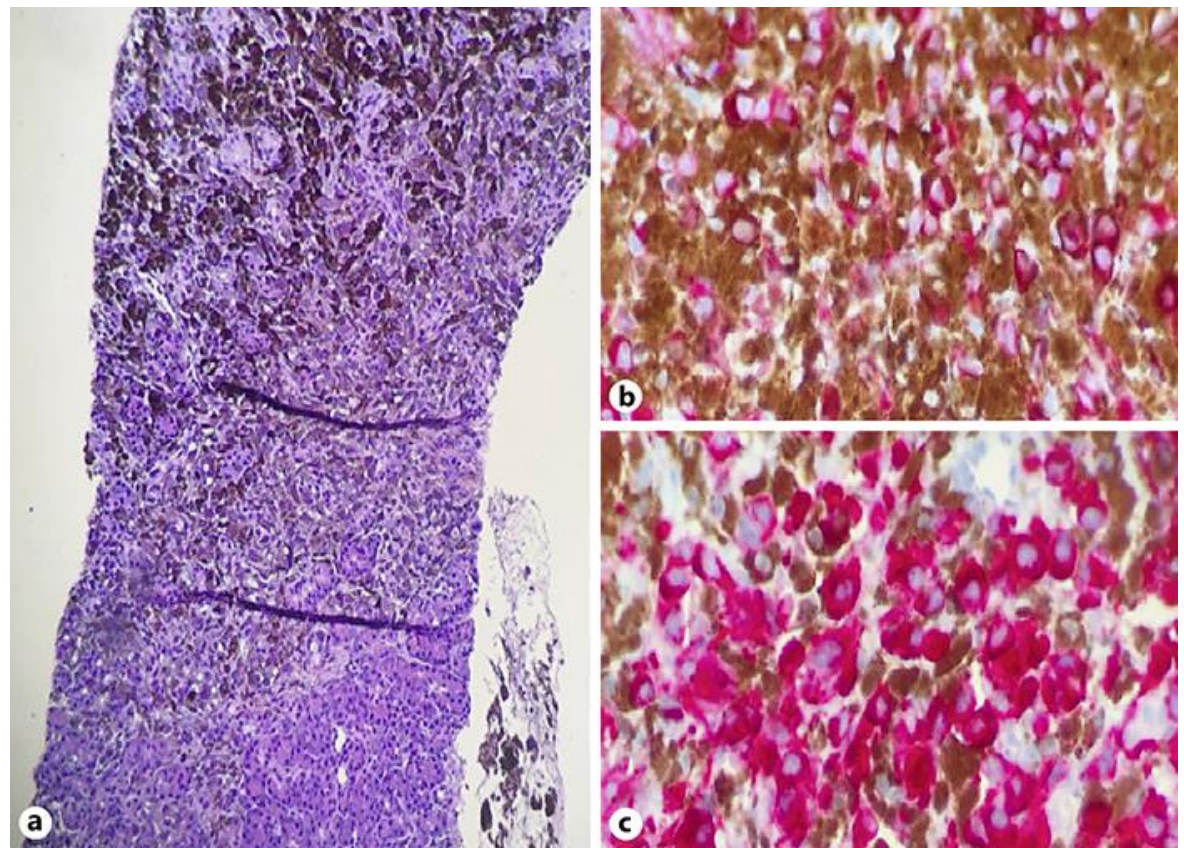

Fig. 3. Fine needle biopsy specimen obtained from the lesion, showing an intense black color. 